\title{
DESCRIPTIVE STUDY OF RATE AND PRESENTATION OF HEARING LOSS IN DISTRICT HOSPITAL- HASSAN
}

Vinay Kumar M. V1, Belure Gowda P. R2, Raghavendra Prasad K. U3, Manohar S. R', Fidelis Gracedass $A^{5}$, Lohith P6, Rakesh P. G

${ }^{1}$ Associate Professor, Department of ENT, Hassan Institute of Medical Sciences, Hassan.

${ }^{2}$ Assistant Professor, Department of ENT, Hassan Institute of Medical Sciences, Hassan.

3 Professor, Department of ENT, Hassan Institute of Medical Sciences, Hassan.

${ }^{4}$ Senior Resident, Department of ENT, Hassan Institute of Medical Sciences, Hassan.

5 Junior Resident, Department of ENT, Hassan Institute of Medical Sciences, Hassan.

${ }^{6}$ Speech Therapist, Department of ENT, Hassan Institute of Medical Sciences, Hassan.

${ }^{7}$ Audiologist, Department of ENT, Hassan Institute of Medical Sciences, Hassan.

ABSTRACT
BACKGROUND
There is not much documenting as of how many hearing loss cases have been reported in district level hospitals in India.
Therefore, a study was undertaken to document the patterns of hearing loss who came to the district hospital of Hassan,
Karnataka, India over a period of 5 years (between Jan 2012 and Dec 2016).

\section{MATERIALS AND METHODS}

Patients who came with the complaints related to ear with hearing loss and willing are all included in this study. All the patients with ear complaints noted with detailed case history and otoscopic examination and basic hearing assessment like Pure Tone Audiometry (PTA), Tympanometry and Otoacoustic Emission (OAE- in case of infant) done to know the rate and presentation of hearing loss.

\section{RESULTS}

Results were analysed in data forms. The mean values were obtained from these data and later converted into percentages across the distribution of the Age, Gender, Causes, Laterality of hearing loss, Type of hearing loss and Degree of hearing loss. In the distribution of different ages, males had higher rates than the females, in the age range 0 - 10 caused highly due to acute otitis media and other age ranges corresponding to different causes. Unilateral hearing loss was higher than the bilateral and mixed type of hearing loss being at the high rate with a degree of hearing loss more at the moderate level.

\section{CONCLUSION}

In this study the patients with hearing disorders with hearing loss had been documented more with presbycusis; it was highest in all the age groups and more with the age of 60 years than the other age groups.

\section{KEYWORDS}

Type, Degree, Hearing Loss, Screening.

HOW TO CITE THIS ARTICLE: Kumar VMV, Gowda BPR, Prasad RKU, et al. Descriptive study of rate and presentation of hearing loss in district hospital- Hassan. J. Evolution Med. Dent. Sci. 2017;6(58):4332-4335, DOI: 10.14260/Jemds/2017/936

\section{BACKGROUND}

Hearing loss due to various ear problems is common in India. It is seen across the various age groups from birth to the old age. The cause and severity may vary. There is no proper documentation. In this study, we are going through the various factors, in which hearing problems were seen. This will help in the proper implementation of the various programs related to hearing and speech problem and also early rehabilitation.

Financial or Other, Competing Interest: None.

Submission 13-06-2017, Peer Review 08-07-2017,

Acceptance 13-07-2017, Published 20-07-2017.

Corresponding Author:

Dr. Vinay Kumar M. V,

Associate Professor,

Department of ENT,

Hassan Institute of Medical Sciences,

Hassan.

E-mail: magicalmagnet@rediffmail.com

DOI: $10.14260 /$ jemds $/ 2017 / 936$

\section{Review of Literature}

Indian Public Health Standards (IPHS) document besides the basic specialty services, due importance has been given to Newborn Care, Physical Medicine and Rehabilitation Services.(1) Documenting newborn screening is important to remember that screening is only the first step in the process of helping those with hearing loss, which achieves good outcome as it is linked to an Early Hearing Detection and Intervention (EHDI) program.(2)

For effective implementation, EHDI programs must rely on an interdisciplinary team approach. Essential team members are families, audiologists, paediatricians and/or primary care physicians, otolaryngologists, speech-language therapists, educators, nurses and community workers.(3)

Patterns of Hearing Loss Presentations in Maitama District Hospitals, Abuja-Nigeria reports inadequate facilities and lack of well-trained manpower are some of the challenges faced.(4) Collaboration at all levels of professional organisations, federal and state governments, hospitals, the medical home and families has contributed to this remarkable success. ${ }^{(5)}$ 
The success of EHDI programs depend on families working in partnership with professionals as a wellcoordinated team. ${ }^{6}$

A study on effects of hearing loss and age of intervention on some language metrics in young hearing impaired children's data is consistent with some of the arguments to be found in the small body of data addressing the question of early intervention.(7) The role of parents and caregivers in seeking early help should be strengthened, while capacity building for the training of more audiologists and speech therapists should be pursued rapidly. ${ }^{(8)}$ Parents were often told that their children were "slow starters" and would outgrow the speech delays only to be enrolled in schools for the deaf when this optimism failed.(9) Organisation for Economic Cooperation and Development (OECD) report states primary prevention of deafness through awareness campaign at the primary care level is still the best option.(10)

\section{MATERIALS AND METHODS}

\section{Study Design}

Descriptive study (observational study) of rate and presentation of hearing loss in district hospital.

\section{Objective}

To document the patterns of hearing loss who came to the district hospital of Hassan, Karnataka, India over a period of 5 years (between 2012 and 2016). Also help to provide proper basic intervention for hearing loss.

\section{Subjects}

Patients who came with the complaint of ear diseases with hearing loss and willing were included. Those who were not willing were excluded.

\section{Materials}

Case history was used to document all the personal and aetiological factors. Otoscopy, Audiometer, Tympanometer and Otoacoustic Emission (OAE- in case of infants) were used to assess ear abnormality and hearing loss.

\section{Procedure}

All the patients with ear complaints noted with detailed case history and otoscopic examination and basic hearing assessment like Pure Tone Audiometry (PTA), Tympanometry and Otoacoustic Emission (OAE) were done to know the patterns of hearing loss.

\section{Analyses}

Results were analysed in both data forms. The mean values was obtained by these data and was converted into percentages across the distribution of the following-

1. Age.

2. Gender.

3. Causal factors.

4. Laterality of hearing loss.

5. Type of hearing loss.

6. Degree of hearing loss.

\section{RESULTS}

\section{Effect of Age}

Results of percentage scores across ages indicated out of 2662 patients. The following are the high scores obtained for each cause in the ascending order.

1. The ages between $0-10$ years.

2. The ages between 21-30 years.

3. The ages between 11-20 years.

4. The ages between 41-50 years.

5. The ages between 31-40 years.

6. The ages between 51-60 years.

7. The ages more than 60 years.

The results are shown in Table I.

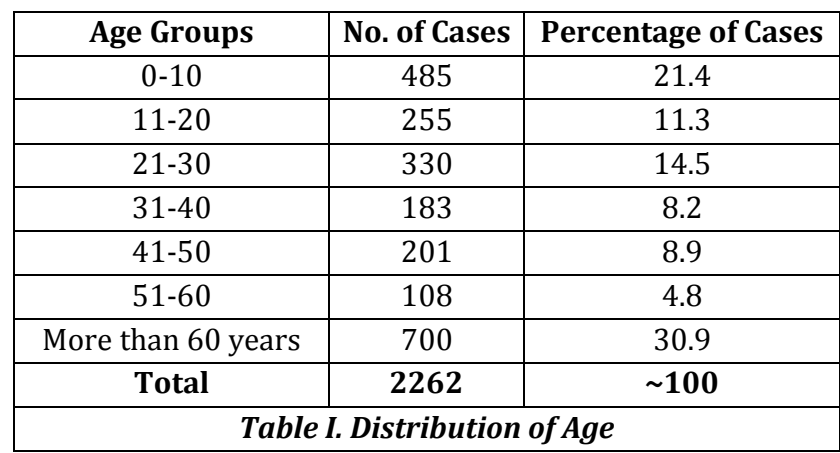

\section{Distribution of Gender}

Results of percentage scores between genders indicated out of 2662 patients, males were higher than female patients.

The results are shown in Table II.

\begin{tabular}{|c|c|c|}
\hline Gender & No. of Cases & Percentage of Cases \\
\hline Males & 1256 & 55.5 \\
\hline Females & 1006 & 44.5 \\
\hline Total & $\mathbf{2 2 6 2}$ & $\sim \mathbf{1 0 0}$ \\
\hline \multicolumn{2}{|c|}{ Table II. Distribution of Gender } \\
\hline
\end{tabular}

\section{Effect of Causes}

Results of percentage scores for different causal factors indicated out of 2662 patients, the following were the high scores obtained for each cause in the ascending order.

1. Acute Otitis Media had higher scores followed by,

2. Otitis Media with Effusion (OME).

3. Chronic Suppurative Otitis Media (CSOM- tubotympanic type).

4. Chronic Suppurative Otitis Media (CSOM- attic antrum type).

5. Wax impaction.

6. Presbycusis.

7. Congenital malformation.

8. Noise-induced hearing loss.

9. Others.

The results are shown in Table III. 


\begin{tabular}{|c|c|c|}
\hline Causal Factors & Total & $\begin{array}{c}\text { Total \% of } \\
\text { Cases }\end{array}$ \\
\hline Acute Otitis Media & 606 & 26.8 \\
\hline Otitis Media with Effusion (OME) & 460 & 20.3 \\
\hline $\begin{array}{c}\text { Chronic Suppurative Otitis Media } \\
\text { (CSOM- tubotympanic type) }\end{array}$ & 290 & 12.9 \\
\hline $\begin{array}{c}\text { Chronic Suppurative Otitis Media } \\
\text { (CSOM- attic antrum type) }\end{array}$ & 218 & 9.6 \\
\hline Wax Impaction & 201 & 8.9 \\
\hline Presbycusis & 191 & 8.4 \\
\hline Congenital Malformation & 171 & 7.6 \\
\hline $\begin{array}{c}\text { Noise-Induced Hearing Loss } \\
\text { (NIHL) }\end{array}$ & 50 & 2.2 \\
\hline Others & 75 & 3.3 \\
\hline Total & $\mathbf{2 2 6 2}$ & $\sim 100$ \\
\hline Table III. Distribution of Causal Factors \\
\hline \multicolumn{2}{|c|}{}
\end{tabular}

6. Profound hearing loss.

7. Normal hearing.

The results are shown in Table VI.

\begin{tabular}{|c|c|c|}
\hline Type of Hearing Loss & $\begin{array}{l}\text { No. of } \\
\text { Cases }\end{array}$ & $\begin{array}{c}\text { Percentage } \\
\text { of Cases }\end{array}$ \\
\hline Normal hearing ( -10 to $15 \mathrm{~dB}$ ) & 183 & 8 \\
\hline Minimal hearing loss (16 to $25 \mathrm{~dB}$ ) & 287 & 12.6 \\
\hline Mild hearing loss (26- $40 \mathrm{~dB})$ & 371 & 16.4 \\
\hline Moderate hearing loss $(41-55 \mathrm{~dB})$ & 446 & 19.8 \\
\hline $\begin{array}{l}\text { Moderately severe hearing loss } \\
(56-70 \mathrm{~dB})\end{array}$ & 411 & 18.2 \\
\hline Severe hearing loss $(71-90 \mathrm{~dB})$ & 288 & 12.8 \\
\hline Profound hearing loss $(>90 \mathrm{~dB})$ & 276 & 12.2 \\
\hline Total & 2262 & $\sim 100$ \\
\hline \multicolumn{3}{|c|}{ Table VI. Type of Hearing Loss } \\
\hline
\end{tabular}

\section{Effect of Laterality of Hearing Loss}

Results of percentage scores for different causal factors indicated out of 2662 patients, unilateral hearing loss were higher than bilateral hearing loss.

The results are shown in Table IV.

\begin{tabular}{|c|c|c|}
\hline $\begin{array}{c}\text { Laterality of Hearing } \\
\text { Loss }\end{array}$ & No. of Cases & $\begin{array}{c}\text { Percentage of } \\
\text { Cases }\end{array}$ \\
\hline Unilateral & 1345 & 59.5 \\
\hline Bilateral & 917 & 40.5 \\
\hline Total & $\mathbf{2 2 6 2}$ & $\sim \mathbf{1 0 0}$ \\
\hline \multicolumn{2}{|c|}{ Table IV. Laterality of Hearing Loss } \\
\hline
\end{tabular}

\section{Effect of Type of Hearing Loss}

Results of percentage scores for different causal factors indicated out of 2662 patients, the following are the high scores obtained for the types of hearing loss in the ascending order.

1. Mixed hearing loss.

2. Conductive hearing loss.

3. Sensorineural hearing loss.

The results are shown in Table V.

\begin{tabular}{|c|c|c|}
\hline Type of Hearing Loss & $\begin{array}{l}\text { No. of } \\
\text { Cases }\end{array}$ & $\begin{array}{c}\text { Percentage } \\
\text { of Cases }\end{array}$ \\
\hline Mixed hearing loss & 815 & 36 \\
\hline Conductive hearing loss & 803 & 35.5 \\
\hline Sensorineural hearing loss & 644 & 28.5 \\
\hline Total & 2262 & $\sim 100$ \\
\hline \multicolumn{3}{|c|}{ Table V. Type of Hearing Loss } \\
\hline
\end{tabular}

\section{Effect of Degree of Hearing Loss}

Results of percentage scores for different causal factors indicated out of 2662 patients, the following are the high scores obtained for the degree of hearing loss-

1. Moderate hearing loss.

2. Moderately severe hearing loss.

3. Mild hearing loss.

4. Severe hearing loss.

5. Minimal hearing loss.

\section{DISCUSSION}

The results indicated two points of interest. First of all, age groups above 60 years were in higher rate of presentation of hearing and related difficulties, especially with complaint of reduced hearing sensitivity. One of the reasons could be the natural ageing phenomenon called Presbycusis, in which the hearing loss increases as age increases. Secondly, more male patients were reported than female because Presbycusis is more seen in male than females. 0-10 years age group had the second highest rate of presentation of hearing loss which is because of upper respiratory tract infections, which causes acute otitis media. Also, there are other causes involved in the other age groups which includes Wax impaction, middle ear infectious conditions like Otitis Media with Effusion (OME), Chronic Suppurative Otitis Media (CSOM- tubotympanic type) and Chronic Suppurative Otitis Media (CSOM- attic antrum type). Noise-induced hearing loss was seen in the age group between 31 - 40 years exclusively.

In case of causal factors most middle ear infectious condition was higher in most age groups because of climatic condition in the Hassan district with Acute Otitis Media being higher followed by other infectious causes followed by wax impaction and other causes. Laterality of hearing loss was seen more with unilateral infections, more likely seen in one ear than the other ears. Since the causal factors are more due to middle ear infections, unilateral hearing loss are seen to be greater than bilateral hearing loss.

Types of hearing loss were seen more with mixed hearing loss because most of the patients with longstanding middle ear infections and came repeatedly to the district hospital with previous treatment. This is followed by conductive hearing loss and sensorineural hearing loss.

Normal hearing was seen in some cases of initial stage of middle ear infections and impacted wax. Rest of the patients mostly had moderate hearing loss, because they noticed the problem. This is followed by moderately severe and severe hearing loss. Minimal hearing loss and profound hearing loss are kind of patients with no hopes as minimal hearing loss patients tend to have difficulty understanding whether they have hearing loss or not and profound hearing loss lose hopes because of communication gap. 


\section{CONCLUSION}

In this study patients with hearing disorders with hearing loss had been documented more with presbycusis; it was highest in all the age groups, more in 60 years than the other age groups. When carrying out such documenting it went smoothly with no problems except for the fact of climatic variation and poor socio-economic status as major issues to the patients. An interesting future study might involve evaluating in different climates, i.e. seasonal variation should document specific type of ear and hearing disorders with rehabilitative measures taken up like cochlear implants, acquisition of hearing aids and its maintenance is still a challenge for the future directions. However, well-trained manpower should be adequate in evaluating the hearing disorders by Speech Language Pathologist cum Audiologist alongside Otologist.

\section{Summary}

The present study was done to document the patterns of hearing loss that came to the district hospital of Hassan, Karnataka, India over a period of 5 years (between 2012 and 2016). The results indicated that age groups more than 60 years are more than the other age groups. Irrespective of causative factor, factors attributing to the middle ear infections such as acute otitis media was higher than the other, which may be associated with unilateral hearing loss more at the moderate level of hearing loss being more than the others. These hearing loss patients can be intervened early either by medical, surgical or rehabilitative methods like hearing aids so that further hearing loss can be prevented.

\section{REFERENCES}

[1] Indian Public Health Standards (IPHS) [Internet] [Updated 12 June, 2012. Available from: URL http://health.bih.nic.in/Docs/Guidelines/GuidelinesDistrict-Hospitals-2012.pdf
[2] Center for Disease Control and Prevention (CDC) [Internet] [Updated 12 November, 2007. Available from:

http://www.cdc.gov/ncbddd/hearingloss/ehdiprograms.html

[3] The Health Professions Council of South Africa (HPCSA) Updated 15 May, 2015. Available from: URL http://www.hpcsa.co.za/Uploads/editor/UserFiles/d ownloads/speech/early_hearing_detection_statement. pdf

[4] Joint committee on infant hearing (JCIH) Updated 02 April 2007. Available from: URL http://www.jcih.org/ExecSummFINAL.pdf

[5] Ahmed M, Audu E. Patterns of hearing loss presentations in Maitama District hospitals AbujaNigeria challenges in Management. 2008. Available from: URL http://www.chha.ca/conference/2008/congress2008 /Patterns_of_Hearing_Loss_in_Maitama_District_Hospi tals_Nigeria).doc

[6] American Academy of Pediatrics, Joint Committee on Infant Hearing. Year 2007 position statement: principles and guidelines for early hearing detection and intervention programs. Paediatric 2007;120(4):898-921.

[7] Ramkalawan TW, Davis AC. The effect of hearing loss and the age of intervention on some language metrics in young hearing impaired children. $\mathrm{Br} \mathrm{J}$ Audiol 1992;26(2):97-107.

[8] Ptok M. Early detection of hearing impairment in newborns and infants. Dtsch Arztebl Int 2011;108(25):426-31.

[9] Olusanya BO, Luxon LM. Childhood deafness poses problems in developing countries. BMJ 2005;330(7489):480-1.

[10] Organisation for Economic Co-operation and Development (OECD) Updated 28 October, 2004. Available from: URL http://www.oecd.org/els/health systems/33865865.pdf 